\title{
Diagnosis and surgical treatment of primary isolated aggressive lumbar myeloid sarcoma: a rare case report and review of the literatures
}

\author{
Cheng-Rui Bai ${ }^{1}$, Xiang Li ${ }^{1}$, Jing-Shi Wang ${ }^{2}$, Jin-Jun $\mathrm{Li}^{1}$, Ning Liu' ${ }^{1}, \mathrm{Qi} \mathrm{Fei}^{1}$, Dong $\mathrm{Li}^{1}$ and Yong Yang ${ }^{1 *}$
}

\begin{abstract}
Background: Myeloid sarcoma is a rare, extramedullary, solid tumor derived from immature myeloid cell precursors. It is most frequently accompanied by acute myelogenous leukemia, though infrequently found in non-acute myelogenous leukemia patients. The tumor may involve any part of the body, but the lumbar spine is seldom involved. The present case study aims to understand the diagnosis and surgical treatment of a rare primary isolated myeloid sarcoma of the lumbar spine causing aggressive spinal cord compression in a non-acute myelogenous leukemia patient.

Case presentation: A 29-year-old man complained of an aggressive radiating pain to the lower extremities and moderate dysuria with a Visual Analogue Scale score that gradually increased from 3 to 8. Lumbar enhanced magnetic resonance imaging and computed tomography revealed a lumbar canal lesion at lumbar spine $L 2$ to $L 4$ with spinal cord compression. A whole body bone scan with fused single photon emission computed tomography/ computed tomography demonstrated abnormal ${ }^{99 \mathrm{~m}} \mathrm{Tc}-$ methylene diphosphonate accumulation in the L3 lamina and spinous process. No evidence of infection or hematology disease was observed in laboratory tests. Due to rapid progression of the symptoms and lack of a clear diagnosis, decompression surgery was performed immediately. During the operation, an approximately $6.0 \times 2.5 \times 1.2 \mathrm{~cm}$ monolithic, fusiform, soft mass in the epidural space and associated lesion tissues were completely resected. The radiating pain was relieved immediately and the dysuria disappeared within 1 week. Intraoperative pathological frozen section analysis revealed a hematopoietic malignant tumor and postoperative immunohistochemistry examination confirmed the diagnosis of myeloid sarcoma.
\end{abstract}

Conclusions: The primary isolated aggressive lumbar myeloid sarcoma is rarely seen, the specific symptoms and related medical history are unclear. Surgery and hematological treatment are effective for understanding and recognizing this rare tumor.

Keywords: Myeloid sarcoma, Acute myelogenous leukemia, Lumbar spine, Decompression surgery, Case report

\footnotetext{
* Correspondence: spineyangyong@sina.com

'Department of Orthopedics, Beijing Friendship Hospital Affiliated of Capital

Medical University, 95 Yong An Rd, Beijing 100050, China

Full list of author information is available at the end of the article
}

\section{$\triangle B M C$}

C C The Author(s). 2021 Open Access This article is licensed under a Creative Commons Attribution 4.0 International License, which permits use, sharing, adaptation, distribution and reproduction in any medium or format, as long as you give appropriate credit to the original author(s) and the source, provide a link to the Creative Commons licence, and indicate if changes were made. The images or other third party material in this article are included in the article's Creative Commons licence, unless indicated otherwise in a credit line to the material. If material is not included in the article's Creative Commons licence and your intended use is not permitted by statutory regulation or exceeds the permitted use, you will need to obtain permission directly from the copyright holder. To view a copy of this licence, visit http://creativecommons.org/licenses/by/4.0/ The Creative Commons Public Domain Dedication waiver (http://creativecommons.org/publicdomain/zero/1.0/) applies to the data made available in this article, unless otherwise stated in a credit line to the data. 


\section{Background}

Myeloid sarcoma (MS) is a rare, extramedullary, solid tumor derived from immature myeloid cell precursors [1]. MS is most frequently accompanied by acute myelogenous leukemia (AML) [2], though infrequently found in non-AML patients, and may further precede the diagnosis of hematology disease [3]. The tumor may involve any part of the body such as the skin, lymph nodes, and bone, but the lumbar spine is seldom involved [4-9]. The present case study aims to understand the diagnosis and surgical treatment of a rare case of primary isolated MS of the lumbar spine causing aggressive spinal cord compression in a non-AML patient.

\section{Case presentation}

Case history, physical examination, diagnostic imaging, and laboratory tests

A 29-year-old man complained of an aggressive radiating pain towards the lower extremities lasting for 1 month. He had no special medical history or fever but had moderate dysuria. Conservative treatment was ineffective. As the radiating pain was aggressive and the Visual Analogue Scale (VAS) [10] score gradually increased from 3 to 8 , the patient had limited mobility in his daily life.

Physical Examination: The patient did not have anemia, subcutaneous bleeding, hepatosplenomegaly, or superficial lymph node enlargement. The spine appeared normal, with a slight limitation of lumbar motion and acute radiating pain that could be evoked by percussing the lumbar (L)2 to L4 spinous processes. The muscular tension, strength of the lower extremities, rectal tone, and perineal sensation were found to be normal. Additionally, the straight leg raising test and all pathological signs were negative.
Diagnostic imaging: Lumbar enhanced magnetic resonance imaging (MRI) revealed a lumbar canal isointense lesion at L2 to L4 and a compressed spinal cord (Fig. 1a, b, c). A computed tomography (CT) scan of the spine showed an iso-dense, fusiform, soft lesion, and slight bone destruction at L2 to L4 (Fig. 1d, e, f). A whole body bone scan with single photon emission computed tomography (SPECT) demonstrated abnormal ${ }^{99 \mathrm{~m}}$ Tc- methylene diphosphonate (MDP) accumulation in the L3 lamina and spinous process on fused SPECT/ CT. No other signs of bone destruction or metastasis were found in the SPECT images (Fig. 2). However, as the exact character of the lesion was not clear from the images of the tumor, hematoma and abscess were not ruled out.

Laboratory tests: The components examined in the blood test were the white blood cells (WBC), $6.01 \times 10^{9} /$ L (3.50-9.50); red blood cells (RBC), $5.00 \times 10^{12} / \mathrm{L}$ (4.30-5.80); hemoglobin (HGB), $158 \mathrm{~g} / \mathrm{L}$ (130-175); platelets (PLT), $236 \times 10^{9} / \mathrm{L}$ (125-350); C-reactive protein $(\mathrm{CRP}), 2 \mathrm{mg} / \mathrm{L}(0-8)$; erythrocyte sedimentation rate (ESR), $4 \mathrm{~mm} / 1 \mathrm{~h}(0-15)$; and procalcitonin (PCT), 0.27 $\mathrm{ng} / \mathrm{ml}(0.00-0.50)$. Brucella tiger red experiment, $\mathrm{T}$-test for tuberculosis infection, and bone marrow biopsy were found to be negative. The results from laboratory tests for infectious and hematological diseases were unclear at this point and obtaining specimens from $\mathrm{CT}$ or ultrasonography-assisted biopsy was unsafe and infeasible due to the highly compressed spinal cord.

\section{Surgery and hematological treatment}

Due to the rapid progression of the symptoms and lack of a clear diagnosis, immediate surgery was performed under general anesthesia to alleviate the symptoms and enable further determination of the diagnosis. During

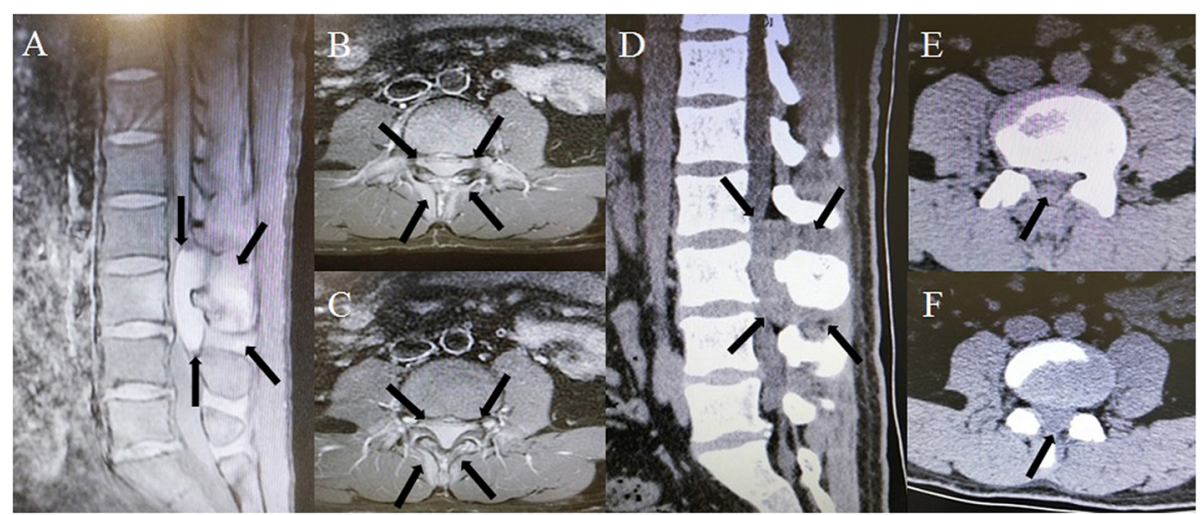

Fig. 1 Preoperative enhanced T1-weighted magnetic resonance images (MRI) of the lumbar spine. a Sagittal and (b) (c) transverse views show an iso-intense, fusiform, high-signal lesion in the L2 to L4 vertebral canal, with complete compression of the local spinal cord and a mixed signal around the L3 lamina, spinous process, and soft tissue. Preoperative computed tomography (CT) of the lumbar spine. $\mathbf{d}$ Sagittal and (e) (f) transverse views show an iso-dense fusiform soft lesion at the L2 to L4 lumbar canal with local spinal cord compression and slight bone destruction.The black arrows show the scope of the lesion 


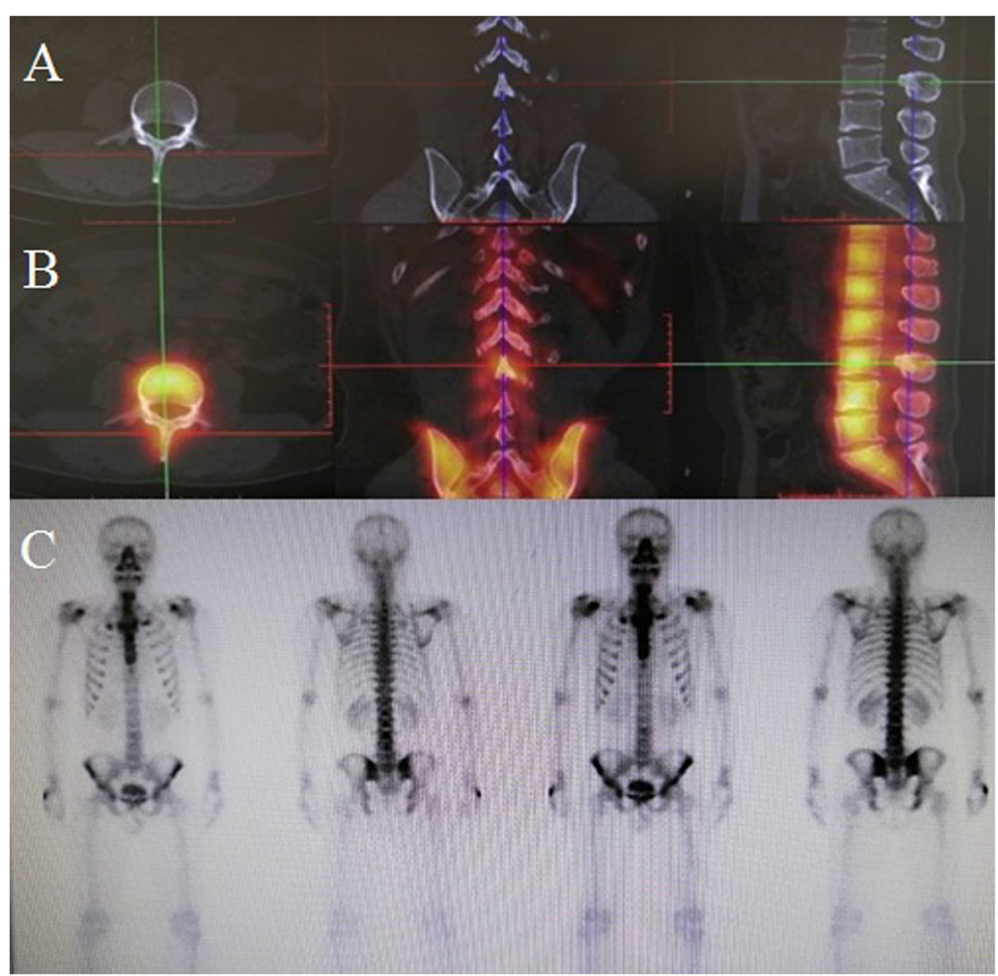

Fig. 2 Preoperative whole body bone scan with single photon emission computed tomography (SPECT). SPECT/CT did not show bone destruction (a). Abnormal ${ }^{99 \mathrm{~m}} \mathrm{Tc}$-methylene diphosphonate (MDP) accumulation was demonstrated in the L3 lamina and spinous process on the fused SPECT/CT (b) and whole body bone scan (c). No signs of other bone destruction and metastasis were observed in the examination

the posterior lumbar operation, the L3 lamina and spinous process were completely resected and the involved L2 and L4 lamina, spinous processes, and tissues were removed. In the present case, the vertebrae body was intact without a corpectomy, although the scan shows vertebrae partial involvement, the stability of the vertebrae body was not obviously destroyed. The procedure of vertebrae corpectomy indicate greater trauma, longer operation time, more bleeding, extra fixation instrument. Considering this conditions, we didn't performed the vertebrae corpectomy. The vertebral canal was later opened and the dura sac was found intact, with no adhesions between the dura sac and mass. Subsequently, the monolithic, irregular, fusiform soft mass with approximate dimensions of $6.0 \times 2.5 \times 1.2 \mathrm{~cm}$ in the epidural space was completely resected (Fig. 3a,b). The dura sac was restored and became engorged and pulsatile immediately (Fig. 3c). During the procedure, the bone structure was partially destroyed, potentially affecting spine stability; thus, screw-rod fixation in L2-L4 was performed (Fig. 3c). A hematopoietic malignant tumor was found in the intraoperative frozen pathological section of the mass after postoperative treatment with hematoxylin and eosin (HE) (Fig. 4a, b). Further, the immunohistochemistry examination showed positive results for cluster of differentiation (CD)33, myeloperoxidase
(MPO) (Fig. 4c, d), Ki67 (30\% +), and CD68 (partial +). Therefore, the diagnosis of MS was confirmed based on the above positive test results.

The radiating pain was relieved shortly after the decompression operation, the VAS decreased to 2 within 1 week, and the dysuria gradually disappeared. After observing these improvements in the patient, he was transferred to the hematology department for further treatment. Although the involved vertebrae was not totally removed, the patients received chemotherapy in the sequent treatment, we hope the residual diseased vertebrae will responds to the chemotherapy [2]. Chemotherapy was performed twice in accordance with the chemotherapy protocol for AML in the hematology department. The chemotherapy regimen consisted of daunorubicin (70 $\mathrm{mg}$ per day) for 3 days and cytosine arabinoside ( $400 \mathrm{mg}$ per day) for 7 days. Bone marrow transplantation was also recommended at an appropriate time after chemotherapy.

At the 3rd month of follow-up, the VAS score was 01 , there was no mass recurrence in repeat MRI (Fig. 3d, e, f), and the screw-rod fixation was in a normal condition (Fig. 3g, h). A bone marrow biopsy showed bone marrow proliferation activity, erythroid hyperplasia, and immunotyping for CD34 (+) and CD117 (+). Early-stage myeloid cells accounted for $0.9 \%$ of the biopsy sample, 


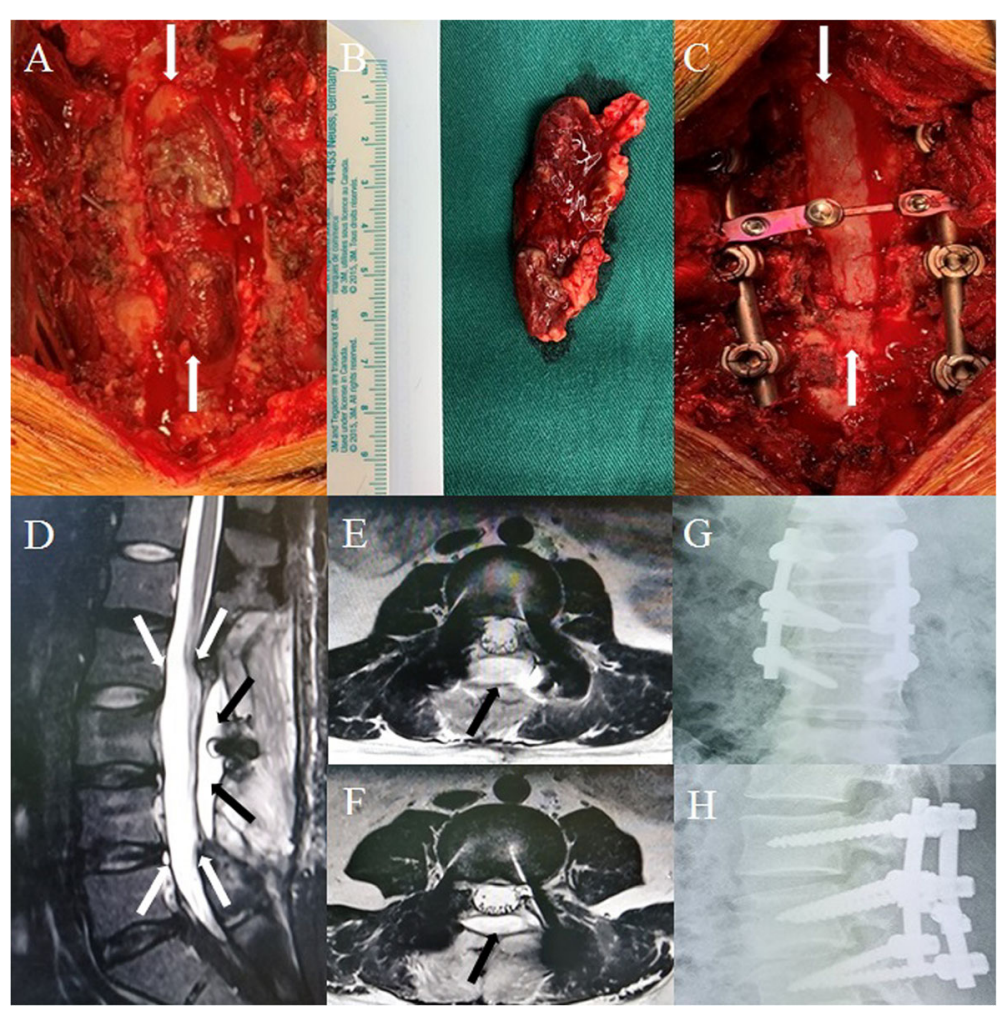

Fig. 3 a The epidural soft mass in the vertebral canal during surgery. The white arrows show the scope of the mass. b The approximately $6.0 \times$ $2.5 \times 1.2 \mathrm{~cm}$ monolithic irregular fusiform soft mass was completely resected. (c) The restored dura sac became engorged and pulsatile after the mass resection. The white arrows show the scope of the dura sac. The postoperative 3rd month magnetic resonance images (MRI) and X-ray images. $\mathbf{d}$ T2-weighted MRI sagittal and (e) (f) transverse views show the dura sac was engorged without any compression. The white arrows show the scope of the engorged dura sac. The black arrows show the postoperative soft tissue changes. No obvious mass relapse was observed. The anteroposterior X-ray image (g) and lateral image (h) show the screw-rod fixation was normal

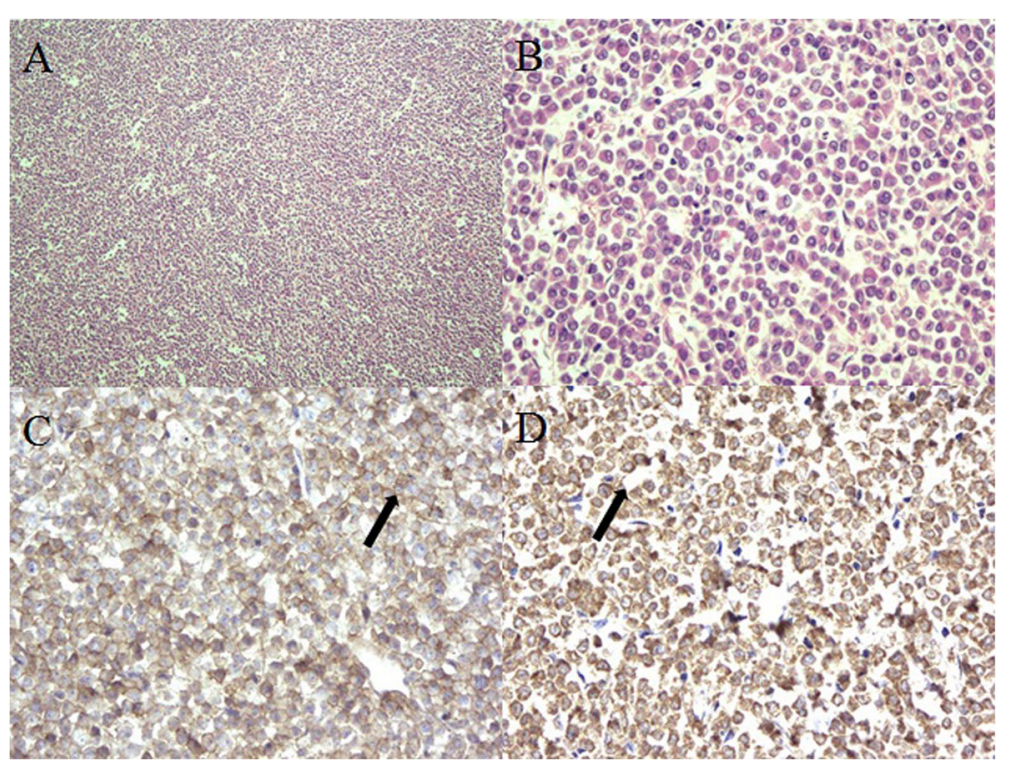

Fig. 4 Hematoxylin and eosin-stained section. a Low power field view (4×10 magnification): diffuse, uniform, heterocytic infiltration and (b) high power field view ( $20 \times 10$ magnification): irregular nuclei and eosinophilic and mitotic figures are easily seen. Immunohistochemistry examination demonstrating (c) the positive expression of cluster of differentiation (CD)33 and (d) positive expression of myeloperoxidase (MPO). The diagnosis of myeloid sarcoma was confirmed. The black arrow shows the positive regions 
with a normal proportion and phenotype. The percentage of granulocytes was $80.7 \%$. Monocytes accounted for $3.1 \%$ and the proportion was normal, mainly comprising CD14 (+) and CD64 (+) mature monocytes. The phenotype was generally normal and the findings were consistent with no AML without bone marrow involvement. Repeat blood routine examination results were also within the normal limits. The patient was judged to be in a healthy condition. At the 10th month of follow-up, the present patient was still in a good and healthy condition with no AML without bone marrow involvement with no local lesion relapse. Indeed, the follow up time was still short, we will continue to focus on the patient, and new clinical outcomes will be reported in the future.

\section{Discussion and conclusions}

MS, previously described as granulocytic sarcoma, myelosarcoma, or chloroma, is a rare, extramedullary solid mass composed of immature myeloid cell precursors [1, 8]. MS can appear in any age group, but shows a slight male predominance [11]. The incidence of MS in adults is particularly low, but it is most frequently accompanied by AML $[2,12]$. In the present case study, the diagnosis of AML was assessed according to the World Health Organization classification for myeloid neoplasms [13]. The diagnosis of MS in the present case was made based on the positive expression of MPO, CD33, Ki67, CD68, the above findings were the surface antigens expression and immunophenotype of immature myeloid cells. MS rarely occurs in patients without bone marrow involvement i.e., AML. The disease often appears as an isolated mass at a single site, known as primary MS, which can precede the diagnosis of hematology disease in individual cases $[3,14]$. The incidence of primary isolated MS is approximately $2 / 1,000,000$ in adults, and 0.7/1,000,000 in children $[11,12]$. The skin, lymph nodes, and bones are the most commonly involved parts and lumbar spine involvement is rare [4-9]. Primary isolated MS involving the lumbar spine canal in the absence of AML is extremely rare $[6,15]$.

In this patient, the symptoms were nonspecific with a lack of hematological disorders, associated history, physical signs, images, and laboratory findings. Obtaining a specimen through non-surgical measures is not feasible and a definite diagnosis is difficult without a sample, particularly in primary isolated MS cases [16]. MS is often misdiagnosed as non-Hodgkin lymphoma, large cell lymphoma, and other undifferentiated carcinoma and there is a $50-75 \%$ rate of misdiagnosis without immunohistochemistry findings $[9,17,18]$. In the present case, we initially speculated about a tumor diagnosis (possibly lymphoma and other spinal cord origin tumors), hematoma, and abscess, without considering the possibility of MS at all. In this crucial situation, immediate surgery was necessary to alleviate the symptoms and also to collect a specimen. The surgical procedure was important and the diagnosis was made by means of the postoperative immunohistochemical findings $[16,18]$.

The optimal treatment for primary isolated MS involving the lumbar spine has not yet been clearly established and there is not enough data with prospective research findings reported in the literature [7]. From the relevant case reports data showed in Table 1, we can find that most of the cases received the treatment including surgery, chemotherapy, radiotherapy, bone marrow transplantation, or any combination of these treatments, no matter there was acute myelogenous leukemia (AML) or not. Early-stage tumor resection surgery can control the local focus and lead to a long asymptomatic period and good response to other treatments, but has no effect on the survival time $[19,20]$. Therefore, surgical treatment alone is not indicated except for patients whose conditions deteriorate under conservative treatment [20].

Isolated MS, as a systemic disease, mostly responds to systemic chemotherapy and surgery for symptomatic MS patients may be considered before starting chemotherapy $[2,21,22]$. The incidence of AML or extramedullary relapse is significantly higher in patients who are only treated with surgery [23]. As MS is rare, the optimal time and protocol for therapy has not been established for isolated MS patients and the chemotherapy regimens are similar to those for AML [2, 24]. Moreover, radiotherapy is necessary for the treatment of isolated MS when the response to chemotherapy is inadequate as well as in cases of recurrence following bone marrow transplantation or for rapid symptom relief [25]. Furthermore, positive results have been reported in some studies for the treatment of isolated MS with bone marrow transplantation and targeted therapy [11, 23, 25]. We think that therapy regimens should be selected according to the characteristic of each case.

Although non-AML MS may have a better survival rate in comparison with AML, the presence of MS is often associated with poor prognosis $[2,7,26]$. The mean survival time for patients with MS ranges between 2.5 and 22 months and is even worse for untreated patients [22]. Hence, careful investigation, rapid and accurate diagnosis, and appropriate treatment should receive the utmost priority in cases of primary isolated MS, which may have a significant impact on the survival rate and prognosis of the patient [22, 27].

To the best of our knowledge, there are no reported cases of primary isolated MS with detailed data regarding the case diagnosis, surgical strategy, and immunohistochemical features in the lumbar spine. A review of the MEDLINE database using the descriptors "spine myeloid sarcoma", "chloroma", "spine granulocytic sarcoma", 


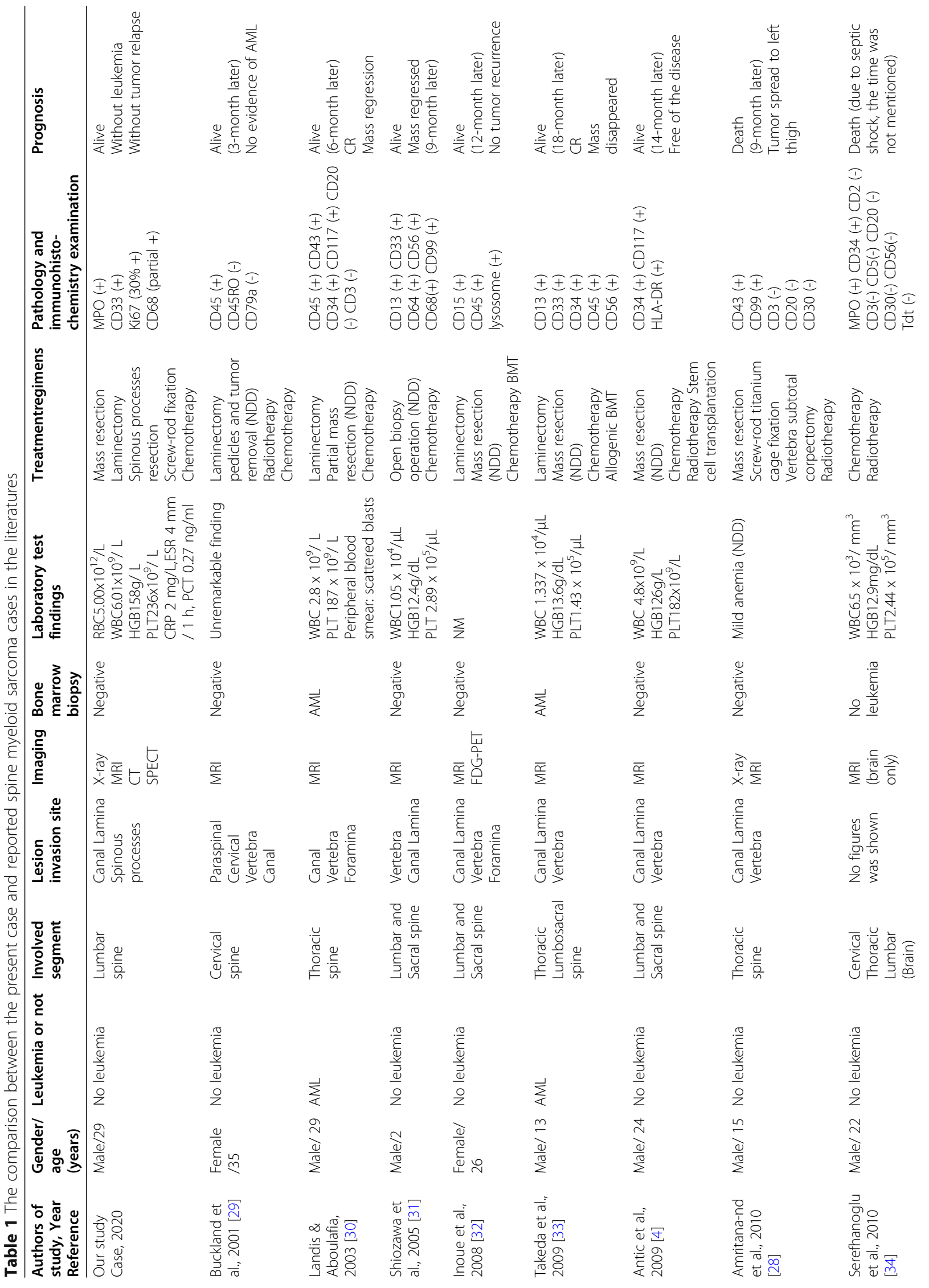




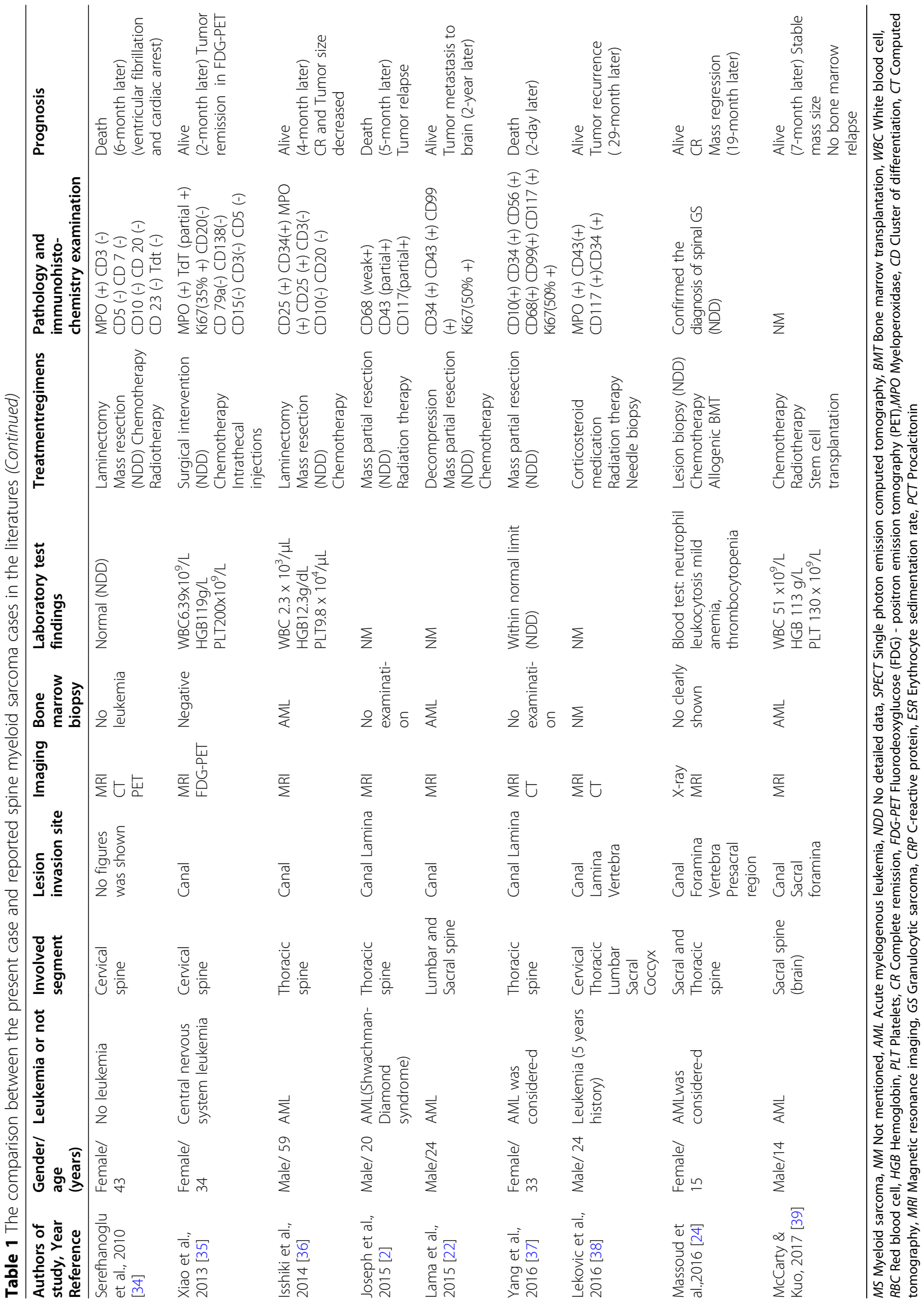


"vertebra canal myeloid sarcoma", and "vertebral canal granulocytic sarcoma" retrieved relevant articles from 2000 to 2020. Upon reviewing the articles (Table 1), 17 MS cases with spine involvement were reported in 16 articles. Although the surface antigens of immature myeloid cells in different types of AML, myeloproliferative diseases, myelodysplastic syndrome and chronic myeloid leukemia are abnormal myeloid antigen expression, they are not completely consistent due to different diseases and types. The immunophenotype of myeloid sarcoma was the same as above. The common positive cell surface antigens of MS include myeloperoxidase (MPO), lysozyme, CD68-kp1, CD117, CD99, CD33, CD34, CD56, CD163, TDT, CD61, CD30, blood group glycoprotein and $\mathrm{CD} 4$. In addition, the positive expression of CD13, CD33, CD117 and MPO often indicates myeloid differentiation of tumor cells, and the positive expression of CD14, CD163 and CD11c indicates the differentiation of monocytes. The diagnoses of the 17 previously reported MS cases were made based on the above findings. Most of these cases had multi-focus involvement of the spine, thoracic region, and sacrum, which are the most frequently involved locations, but single lumbar spine involvement was absent. Only one case of thoracic spine MS was reported and a detailed description of the diagnosis and imaging was provided, especially the surgical treatment tactics $[2,4,22,24,28-39]$.

The differences in history, clinical manifestation, lesion morphology, surgical methods, and prognosis were also quite significant between previous cases and the present case. Compared to previous reports, primary isolated lumbar spine involvement at a single site and more comprehensive clinical data regarding the case exhibition and surgical procedure description were presented in this case study. However, further hematologic treatment was not completely provided and the final outcome was not observed before the manuscript was submitted due to the short follow-up period in the present case. This is the limitation of our case report.

Conclusions: As primary isolated aggressive lumbar MS is rarely seen, the specific symptoms and related medical history are unclear. Hence, accurate diagnosis is challenging. However, in the present case study, immediate surgery played an important role in specimen collection and the patient's symptoms were quickly alleviated. The prognosis of primary isolated lumbar spine MS is generally poor. However, rapid and accurate diagnosis provides the basis for further treatment and appropriate hematologic treatment should receive the utmost priority to improve the long-term outcomes. As our case study is rare and specific, this report will improve the understanding and recognition of the rare tumor in the future.

\section{Abbreviations}

MS: Myeloid sarcoma; NM: Not mentioned; AML: Acute myelogenous leukemia; NDD: No detailed data; SPECT: Single photon emission computed tomography; BMT: Bone marrow transplantation; WBC: White blood cell; RBC: Red blood cell; HGB: Hemoglobin; PLT: Platelets; CR: Complete remission; FDG-PET: Fluorodeoxyglucose (FDG) - positron emission tomography (PET); MPO: Myeloperoxidase; CD: Cluster of differentiation; $C T$ : Computed tomography; MRI: Magnetic resonance imaging;

GS: Granulocytic sarcoma; VAS: Visual analogue scale; CRP: C-reactive protein; ESR: Erythrocyte sedimentation rate; PCT: Procalcitonin; HE: Hematoxylin and eosin

\section{Acknowledgements \\ We thank the staff at the Department of Orthopedics, the Department of Hematology, the Department of Pathology, the Department of Nuclear Medicine, and the Library in Beijing Friendship Hospital, Capital Medical University. The authors would like to express their sincere thanks to Medjaden Bioscience Limited Company for providing writing and editorial assistance.}

\section{Authors' contributions}

All authors read, edited and approved the final manuscript. CRB and YY were the lead investigator, and developed the design of the study, carried out data-acquisition, analysis, interpretations, and prepared the manuscript. XL and JSW were responsible for the design, project supervision and writing of the manuscript. JJL, NL, QF and DL assisted in carrying out data acquisition and was involved in preparing the study design and in writing the manuscript.

\section{Funding}

No funding.

Availability of data and materials

Data sharing is within the manuscript.

\section{Ethics approval and consent to participate}

The study protocol was approved by our institution's ethics committee (Bioethics Committee of Beijing Friendship Hospital,Capital Medical University), and written informed consent was obtained from all participating patients. There are no ethical/legal conflicts involved in the article.

\section{Consent for publication}

This paper has not been published elsewhere in whole or in part, or submitted elsewhere for review. All authors have read and approved the content and are accountable for all aspects of the accuracy and integrity of the manuscript in accordance with ICMJE criteria, and agree to submit it for consideration for publication in the Journal of BMC Musculoskeletal Disorders. The written consent to publish this information was obtained from study participants, and the proof of consent to publish from study participants can be requested at any time.

\section{Competing interests}

The authors declare that they have no competing interests.

\section{Author details}

${ }^{1}$ Department of Orthopedics, Beijing Friendship Hospital Affiliated of Capital Medical University, 95 Yong An Rd, Beijing 100050, China. ²Department of Hematology, Beijing Friendship Hospital Affiliated of Capital Medical University, 95 Yong An Rd, Beijing 100050, China.

Received: 20 May 2020 Accepted: 9 February 2021

Published online: 24 February 2021

\section{References}

1. Klco JM, Welch JS, Nguyen TT, Hurley MY, Kreisel FH, Hassan A, Lind AC, Frater JL. State of the art in myeloid sarcoma. Int J Lab Hematol. 2011;33(6): 555-65.

2. Joseph JR, Wilkinson DA, Bailey NG, Lieberman AP, Tsien Cl, Orringer DA. Aggressive myeloid sarcoma causing recurrent spinal cord compression. World Neurosurg. 2015;84(3):866.e7-10. 
3. Pileri SA, Ascani S, Cox MC, Campidelli C, Bacci F, Piccioli M, Piccaluga PP, Agostinelli C, Asioli S, Novero D, Bisceglia M, Ponzoni M, Gentile A, Rinaldi P, Franco V, Vincelli D, Pileri A Jr, Gasbarra R, Falini B, Zinzani PL, Baccarani M. Myeloid sarcoma:clinico-pathologic, phenotypic and cytogenetic analysis of 92 adult patients. Leukemia. 2007;21(2):340-50

4. Antic D, Verstovsek S, Elezovic I, Grujicic D, Gotic M, Bila J, Perunicic M, Jakovic L. Spinal epidural granulocytic sarcoma in non-leukemic patient. Int J Hematol. 2009:89(1):95-7.

5. Balleari E, Panarello S, Capello E, Grosso M, Passalia C, Pitto P, Raggi F, Roccatagliata L, Cabiddu F, Ghio R. Granulocytic sarcoma: an unusual cause of spinal cord compression. Int J Clin Oncol. 2007;12(3):234-7.

6. Chamberlain MC, Tredway TL, Born D, Fink J. Teaching neuroimages: sacral spine chloroma. Neurology. 2013;81(11):e87.

7. Yilmaz AF, Saydam G, Sahin F, Baran Y. Granulocytic sarcoma: A systematic review. Am J Blood Res. 2013:3(4):265-70.

8. Wang W, He HS, Chen XW, Zhang CH. Primary bronchial myeloid sarcoma mimicking bronchogenic carcinoma: a case report. BMC Pulm Med. 2019. 19(1):204.

9. Alexiev BA, Wang W, Ning Y, Chumsri S, Gojo I, Rodgers WH, Stass SA, Zhao XF. Myeloid sarcomas: a histologic, immunohistochemical, and cytogenetic study. Diagn Pathol. 2007;2:42.

10. Kliger M, Stahl S, Haddad M, Suzan E, Adler R, Eisenberg E. Measuring the intensity of chronic pain: Are the visual analogue scale and the verbal rating scale interchangeable? Pain Pract. 2015;15(6):538-47.

11. Almond LM, Charalampakis M, Ford SJ, Gourevitch D, Desai A. Myeloid sarcoma: Presentation, diagnosis, and treatment. Clin Lymphoma Myeloma Leuk. 2017;17(5):263-7.

12. Kim SC, Natarajan-Ame S, Lioure B, Chenard MP, Duclos B, Herbrecht R, Bergerat JP. Successful treatment of a granulocytic sarcoma of the uterine cervix in complete remission at six-year follow-up. J Oncol. 2010;2010: 812424

13. Arber DA, Orazi A, Hasserjian R, Thiele J, Borowitz MJ, LeBeau MM, Bloomfield CD, Cazzola M, Vardiman JW. The 2016 revision to the World Health Organization classification of myeloid neoplasms and acute leukemia. Blood. 2016;127(20):2391-405.

14. Tan D, Wong GC, Koh LP, Hwang W, Loh Y, Linn YC, Goh YT. Successful treatment of primary granulocytic sarcoma by non-myeloablative stem cell transplant. Leuk Lymphoma. 2006;47(1):159-62.

15. Baikaidi M, Chung SS, Tallman MS, Damon LE, Walker AR, Marcucci G, Sholi AM, Morris GJ. A 75-year-old woman with thoracic spinal cord compression and chloroma (granulocytic sarcoma). Semin Oncol. 2012;39(6):e37-46.

16. Norsworthy KJ, Bhatnagar B, Singh ZN, Gojo I. Myeloid sarcoma of the hepatobiliary system: A case series and review of the literature. Acta Haematol. 2016;135(4):241-51.

17. Audouin J, Comperat E, LeTourneau A, Camilleri-Broët S, Adida C, Molina T, Diebold J. Myeloid sarcoma: clinical and morphologic criteria useful for diagnosis. Int J Surg Pathol. 2003;11(4):271-82.

18. Meis JM, Butler JJ, Osborne BM, Manning JT. Granulocytic sarcoma in nonleukemic patients. Cancer. 1986;58(12):2697-709.

19. Buckland ME, Scolyer RA, Donellan MB, Brew S, McGee-Collett M, Harper CG. Spinal chloroma presenting with triplegia in an aleukaemic patient. Pathology. 2001;33(3):386-9.

20. Landis DM, Aboulafia DM. Granulocytic sarcoma: an unusual complication of aleukemic myeloid leukemia causing spinal cord compression. A case report and literature review. Leuk Lymphoma. 2003;44(10):1753-60.

21. Shiozawa Y, Kiyokawa N, Saito M, Fujimoto J, Hata Jl, Yamashiro Y. Granulocytic sarcoma of the spine in a child without bone marrow involvement: a case report and literature review. Eur J Pediatr. 2005;164(10): $616-20$

22. Inoue T, Takahashi T, Shimizu H, Kanamori M, Kumabe T, Watanabe M, Tominaga T. Spinal granulocytic sarcoma manifesting as radiculopathy in a nonleukemic patient. Neurol Med Chir (Tokyo). 2008;48(3):131-6.

23. Takeda M, Yamaguchi S, Eguchi K, Kajiume T, Nishimura S, Kobayashi M, Kurisu K. Spinal epidural granulocytic sarcoma in a child precedent to clinical manifestation of acute myeloid lymphoma: case report. Neurol Med Chir (Tokyo). 2009;49(5):221-2.

24. Amritanand R, Venkatesh K, Premkumar AJ, Sundararaj GD. Pathological dislocation of the dorsal spine following granulocytic sarcoma in a nonleukaemic patient. Eur. Spine J. 2010;19(Suppl 2):S114-7.
25. Serefhanoglu S, Goker H, Aksu S, Buyukasik Y, Sayinalp N, Haznedaroglu IC Ozcebe Ol. Spinal myeloid sarcoma in two non-leukemic patients. Intern Med. 2010;49(22):2493-7.

26. Xiao RZ, Long ZJ, Xiong MJ, Wang WW, Lin DJ. Diagnosis and treatment of a patient with isolated spinal granulocytic sarcoma: A case report. Oncol Lett. 2013;5(4):1229-32.

27. Isshiki Y, Ohwada C, Togasaki E, Shimizu R, Hasegawa N, Yamazaki A, Sugita Y, Kawaguchi T, Tsukamoto S, Sakai S, Takeda Y, Takeuchi M, Sakaida E, Shimizu N, Ota S, Yokote K, Iseki T, Nakaseko C. Acute myeloid leukemia concurrent with spinal epidural extramedullary myeloid sarcoma accompanied by a high CD25 expression and the FLT3-ITD mutation. Intern Med. 2014;53(11):1159-64.

28. Lama S, Lui SU, XiaoY ZHW, Karki M, Gong QY. Sacral myeloid sarcoma involving multiple metastases to the brain: A case report. Exp Ther Med. 2015:9(4):1429-32.

29. Yang CL, Fang JY. Xu Y. Isolated spinal myeloid sarcoma with rapid progression. Spine J. 2016;16(8):e517-8.

30. Lekovic GP, Schwartz MS, Go JL. Multifocal granulocytic sarcoma of the spine mimicking neurofibromatosis Type 2: case report. J Neurosurg Spine. 2016;25(4):523-7.

31. Massoud M, Del Bufalo F, Caterina Musolino AM, Maria Schingo P, Gaspari S, Pisani M, Orazi C, Reale A, Raucci U. Myeloid sarcoma presenting as low back pain in the pediatric emergency department. J Emerg Med. 2016;51(3): 308-14.

32. McCarty SM, Kuo DJ. Persistent sacral chloroma in refractory acute myelogenous leukaemia. BMJ Case Rep. 2017;6:bcr2017219936. Published online 2017 Jul 6. https://doi.org/10.1136/bcr-2017-219936.

33. Lee SH, Park J, Hwang SK. Isolated recurrence of intracerebral granulocytic sarcoma in acute lymphoblastic leukemia: a case report. J Neurooncol. 2006; 80(1):101-4.

34. Eom KS, Kim TY. Intraparenchymal myeloid sarcoma and subsequent spinal myeloid sarcoma for acute myeloblastic leukemia. J Korean Neurosurg Soc. 2011:49(3):171-4.

35. Bakst RL, Tallman MS, Douer D, Yahalom J. How I treat extramedullary acute myeloid leukemia. Blood. 2011;118(14):3785-93.

36. Antic D, Elezovic I, Milic N, Suvajdzic N, Vidovic A, Perunicic M, Djunic I, Mitrovic M. Tomin D. Is there a "gold" standard treatment for patients with isolated myeloid sarcoma? Biomed Pharmacother. 2013;67(1):72-7.

37. Magdy M, Abdel Karim N, Eldessouki I, Gaber O, Rahouma M, Ghareeb M. Myeloid sarcoma. Oncol Res Treat. 2019;42(4):224-9.

38. Shimizu H, Saitoh T, Hatsumi N, Takada S, Yokohama A, Handa H, Jimbo T, Sakura T, Tsukamoto N, Murakami H, Miyawaki S, Nojima Y. Clinical significance of granulocytic sarcoma in adult patients with acute myeloid leukemia. Cancer Sci. 2012;103(8):1513-7.

39. Paydas S, Zorludemir S, Ergin M. Granulocytic sarcoma: 32 cases and review of the literature. Leuk Lymphoma. 2006:47(12):2527-41.

\section{Publisher's Note}

Springer Nature remains neutral with regard to jurisdictional claims in published maps and institutional affiliations.

Ready to submit your research? Choose BMC and benefit from:

- fast, convenient online submission

- thorough peer review by experienced researchers in your field

- rapid publication on acceptance

- support for research data, including large and complex data types

- gold Open Access which fosters wider collaboration and increased citations

- maximum visibility for your research: over $100 \mathrm{M}$ website views per year

At $\mathrm{BMC}$, research is always in progress.

Learn more biomedcentral.com/submissions 